\title{
A Comparative Studyof Cellulose Agricultural Wastes (Almond Shell, Pistachio Shell, Walnut Shell, Tea waste and Orange Peel) for Adsorption of Violet B dye from Aqueous Solutions
}

\author{
SAEEDEH HASHEMIAN* and JALAL SHAYEGAN² \\ 1Department of Chemistry, Islamic Azad University, Yazd Brunch, Yazd, Iran \\ ${ }^{2}$ Sharif University of Technology, Chemical and Petroleum Engineering Department, Tehran, Iran \\ ${ }^{*}$ Corresponding author E-mail: Sa_hashemian@ iauyazd.ac.ir
}

http://dx.doi.org/10.13005/ojc/300478

(Received: May 20, 2014; Accepted: July 15, 2014)

\begin{abstract}
Adsorption of violet $B$ azo dye from aqueous solutions was studied by different cellulose agricultural waste materials (almond shell (AS), pistachio shell (PS), walnut shell (WS), Tea waste (TW) and orange peel (OP)). Cellulose agriculturalwaste sorbents characterized by FTIR and SEM methods. The effects of different parameters such as contact time, $\mathrm{pH}$, adsorbent dosage and initial dye concentration were studied.Maximum removal of dye was obtained at contact time of $90 \mathrm{~min}$ and $\mathrm{pH} 11$. The adsorption of violet $\mathrm{B}$ was fitted by pseudo-second-order kinetic model.The Langmuir isotherm model was better fitted than Freundlichmodel. The results showed that the adsorption efficiency of violet B by cellulose agriculturalwaste materials isas followed: Almond shell > Orange peel $>$ Pistachio shell $>$ Tea waste $>$ Walnut shell. The maximum adsorption capacity wasobtained 96, 82, 71.4, 55.5 and $48.7 \mathrm{mg} \mathrm{g}$ "1 for AS, OP, PS, TW and WS, respectively.
\end{abstract}

Key words: Adsorption, Agricultural wastes,Cellulose-based wastes, Violet B

\section{INTRODUCTION}

Many industries such as textile, paint, paper, plastics, leather, food and cosmetic often use dyes and pigments to color their products. Most of synthetic dyes have complexaromatic molecular structures. Dyes can cause allergicdermatitis, skin irritation, cancer, mutation, etc. Dyes also are highly toxic to some organismsand hence disturb the ecosystem $^{1,2}$. Dyes are usually stable to biodegradation, photo-degradation, and oxidizing agents $^{3}$, which led to intensive investigations on different methods to remove color from dye effluent. These studies include the use of coagulants ${ }^{4}$, ultrafiltration $^{5}$ and electro-chemical ${ }^{6,7}$. Adsorption methods, are the most widely used techniques ${ }^{8-12}$. The advantagesand disadvantages of each technique have been extensivelyreviewed. Of these methods, adsorption has been found tobe an efficient and economic process to remove dyes, pigmentsand other colorants and also to control the bio-chemical oxygendemand ${ }^{13}$. Extensive 
research has been carried out during the last ten years to find low-cost, high capacity adsorbents for the removal of dyes ${ }^{14-16}$.

Adsorption has been described as an effective separation process for treating industrial and domestic effluents. It is widely used as effective physical method of separation in order to eliminate or lower the concentration of a wide range of dissolved pollutants (organics or inorganics) in the effluent.The use of cheap and ecofriendly adsorbents wasstudied as an alternative substitution ofactivated carbon for removal of dyes from wastewater. The agricultural and forestry waste products represent unused resources and also they are widely available.

Different kinds of activated carbon have been achieved from different agriculture wastes and used as low-cost adsorbents for removal of organic compounds and dyes from aqueous solution ${ }^{17-23}$. Almond is one of the important agricultural materials. The shells of almond are waste materials and generally discarded as a waste. It can be collected on community basis for reuse. Almond shells are abundant, inexpensive and readily available lignocellulosic material. Almond shells can be used as sorbent. The cell walls of almond shell consist of cellulose, silica, lignin and carbohydrates which have hydroxyl groups in their structures ${ }^{24-26}$. Orange, as a kind of biological resources is available in large quantities in many parts of the world. Dried orange peel was previously investigated to adsorb acid violet 17 and Direct Red $23^{27,28}$.

The purpose of this work was to test the possibility and comparative study of using cellulosebased wastes (almond shell, pistachio shell, walnut shell, tea waste and orange peel) for adsorption of violet $\mathrm{B}$ dye.

\section{EXPERIMENTAL}

\section{Materials and Method}

Soft pistachio shell, almond shell, walnut shell, waste tea and orange peel (PS, AS, WS, WT, OP) were used as cellulose agricultural waste materials. Pistachio shell,almond shell and walnut shell were collected from a local center of preparation of shell-removed (IRAN- Yazd). Orange peels were collected from a local fruit field in the south of Iran. The collected biomaterial was extensively washed under tap water to remove any particulate sprayed with distilled water. The tea waste was washed with tap water and distilled water for several times to remove all the dirt particles. It was then boiled with distilled water to remove caffeine, tannin and other dyes and washed with distilled water till the washing water contains no color. The shells were preheated in an oven at $100{ }^{\circ} \mathrm{C}$ for about $48 \mathrm{~h}$ to reduce the moisture content. Cellulose agricultural wastes were cut into small pieces. After sieving the particle size of materials was remained between $1-5 \mathrm{~mm}$. Some of properties of cellulose agricultural wastes are summarized in Table. 1.

All chemicals were analytical reagent grade. Distillated waster was used at all of experiments. 1-Naphthalenesulfonic acid, 3-((4'-((2amino-8-hydroxy-6-sulfo-1-naphthalenyl)azo)(1,1'biphenyl)-4-yl)azo)-4-hydroxy-, disodium salt (Violet B) was purchased from Merck. Violet B is double azo class with molecular formula of $\mathrm{C}_{32} \mathrm{H}_{21} \mathrm{~N}_{5} \mathrm{Na}_{2} \mathrm{O}_{8} \mathrm{~S}_{2}(\mathrm{MW}=713.65)$. It was used as received without further purification. The stock solution of $1000 \mathrm{mg} \mathrm{L}^{-1}$ of VB dye was prepared in double distilled water. The dilution was done in distilled water when necessary. Chemical structure of Violet $B$ is shown in Fig. 1. The percent removal of Violet $\mathrm{B}$ by the hereby adsorbent is given by:

$\%$ Removal $=\left(\mathrm{C}_{0}-\mathrm{C}_{\mathrm{e}}\right) / \mathrm{C}_{0} \times 100$

Where $\mathrm{C}_{0}, \mathrm{C}_{e}$ denotes the initial and equilibrium dye concentration (mg $\left.\mathrm{L}^{-1}\right)$.

IR measurements were performed by FTIR tensor-27 of Burker Co. Pressed pellets were prepared by grinding the powder specimens with spectroscopic grade $\mathrm{KBr}$ for FTIR spectra test. UVVis spectrophotometer 160 A Shimadzu was used for determination of concentration of dye. Scanning electron microscopy was performed using a Philips SEM model XL30 electron microscope. The $\mathrm{pH}$ was adjusted by addition of $\mathrm{HCl}$ or $\mathrm{NaOH}$. All $\mathrm{pH}$ measurements were carried out with an ISTEK$720 \mathrm{P} \mathrm{pH}$ meter. The suspensions containing $1.0 \mathrm{~g}$ of the sorbent with varying amounts of dye was shaken in an orbital shaker at $150 \mathrm{rpm}$. 


\section{RESULT AND DISCUSSION}

\section{Characterization of adsorbent}

FTIR spectrum of cellulose agricultural wastes (a-Orange peel, b-Almond shell, c-Pstahio shell, d- walnut shell and e- Teawaste) are shown in Fig. 2. The broad peak around $3367-3410 \mathrm{~cm}^{-1}$ correspond to $\mathrm{O}-\mathrm{H}$ stretching vibrations, due to inter and inter-molecular hydrogen banding of polymeric compounds (macromolecular associations), such as alcohols, phenols and carboxylic acids, as in pectin, cellulose groups on the adsorbent surface. The peaks at $2916 \mathrm{~cm}^{-1}$ and $2924 \mathrm{~cm}^{-1}$ are attributed to the symmetric and asymmetric $\mathrm{C}-\mathrm{H}$ stretching vibration of aliphatic acids. The peak observed around at $1630 \mathrm{~cm}^{-1}$ is the stretching vibration of bond due to non-ionic carboxyl groups $(-\mathrm{COOH},-$ $\mathrm{COOCH}_{3}$ ), and may be assigned to carboxylic acids

Table 1: Some of properties of cellulose agricultural wastes

\begin{tabular}{lccccc}
\hline Parameters & \multicolumn{3}{c}{ Values } \\
\cline { 2 - 5 } & Almond shell & Pistachio shell & Walnut shell & Orange peel & Tea waste \\
\hline Carbon (\%) & 53.3 & 51.2 & 48.4 & 52.9 & 48.95 \\
Oxygen (\%) & 41.4 & 42.5 & 46.6 & 41.8 & 45.8 \\
Hydrogen (\%) & 5.2 & 5.3 & 4.95 & 5.1 & 5.1 \\
Ash content (\%) & 2.2 & 0.8 & 3.1 & 12.2 & 1.7 \\
Moisture content (\%) & 2.3 & 4.92 & 3.8 & 18.5 & 3.4 \\
Surface area (m $\left.\mathrm{g} \mathrm{g}^{-1}\right)$ & 34.5 & 17.8 & 6.8 & 22.56 & 7.3 \\
Pore volume $\left(\mathrm{ml} \mathrm{g}^{-1}\right)$ & 0.75 & 0.71 & 0.67 & 0.73 & 0.68 \\
Density $\left.(\mathrm{g} \mathrm{cm})^{3}\right)$ & 1.9 & 1.4 & 1.1 & 1.75 & 1.2 \\
Particle size $\left(\mathrm{mm}^{2}\right)$ & $1-5$ & $1-5$ & $1-5$ & $1-5$ & $1-5$ \\
\hline
\end{tabular}

Table 2: Kinetic parameters for adsorption of violet $B$ bycellulose agricultural wastes

\begin{tabular}{lccccc}
\hline \multirow{2}{*}{ Sorbents } & \multicolumn{2}{c}{ First order } & & \multicolumn{2}{c}{ Second order } \\
\cline { 2 - 3 } \cline { 5 - 6 } & $\mathbf{R}^{2}$ & $\mathbf{K}_{1}\left(\mathbf{m i n}^{-1}\right)$ & & $\mathbf{R}^{2}$ & $\mathbf{K}_{2}\left(\mathbf{g ~ m g ~}^{-1} \mathbf{m i n}^{-1}\right)$ \\
\hline \multirow{2}{*}{ AS } & 0.915 & $1.9 \times 10^{-2}$ & & 0.996 & 36.76 \\
OP & 0.94 & $1.3 \times 10^{-2}$ & & 0.991 & 25.3 \\
PS & 0.92 & $2.0 \times 10^{-2}$ & & 0.994 & 9.13 \\
TW & 0.906 & $1.1 \times 10^{-2}$ & & 0.991 & 1.04 \\
WS & 0.87 & $9.0 \times 10^{-3}$ & & 0.992 & 0.968 \\
\hline
\end{tabular}

Table 3: Langmuir and Freundlich isotherm constants for adsorption ofviolet $B$ bycellulose agriculturalwastes (walnut shell (WS), Pstahio shell (PS), Orange peel(OP), Tea waste (TW) and Almond shell (AS))

\begin{tabular}{lccccccc}
\hline \multirow{2}{*}{ Sorbent } & \multicolumn{3}{c}{ Freundlich } & & \multicolumn{3}{c}{ Langmuir } \\
\cline { 2 - 4 } \cline { 7 - 8 } & $\mathbf{K}_{\mathrm{F}}$ & $\mathbf{n}$ & $\mathbf{R}^{2}$ & & $\mathbf{q}_{\mathrm{m}}\left(\mathbf{m g ~ g}^{-1}\right)$ & $\mathbf{K}_{\mathrm{L}}\left(\mathbf{L ~ m g ~}^{-1}\right)$ & $\mathbf{R}^{2}$ \\
\hline AS & 0.723 & 8.36 & 0.653 & 96 & 168.5 & 0.991 \\
OP & 0.76 & 7.3 & 0.85 & & 82 & 155.4 & 0.978 \\
PS & 0.824 & 14.34 & 0.92 & & 71.4 & 166.6 & 0.986 \\
TW & 0.88 & 13.4 & 0.83 & & 55.5 & 124.6 & 0.98 \\
WS & 0.96 & 10.5 & 0.78 & & 48.7 & 116 & 0.978 \\
\hline
\end{tabular}


or their esters. Broad peak at $1040-1070 \mathrm{~cm}^{-1}$ may be due to stretching vibration of $\mathrm{C}-\mathrm{OH}$ of alcoholic groups and carboxylic acids ${ }^{29-30}$.

The SEM images of cellulose agricultural wastes (walnut shell (WS), Pstahio shell (PS), Orange peel(OP), Tea waste(TW) and Almond shell (AS)) are shown in Fig 3.

The SEM images obviously are shown the porous nature cellulose agricultural wastes.

\section{Adsorption study \\ Effect of contact time}

Effect of contact time on the adsorption of violet $B$ by Almond shell (AS), Pstahio shell (PS), Orange peel (OP), Tea waste(TW) and walnut shell (WS) was studied at different times (0-600 min). 50 $\mathrm{mL}$ of $30 \mathrm{mg} \mathrm{L}^{-1}$ of violet $B$ and $1.0 \mathrm{~g}$ of waste shells was used. After different agitation times, absorbance

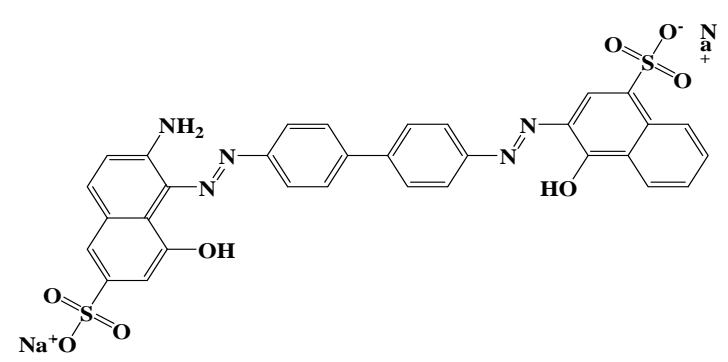

Fig. 1: Chemical structure of violet B of filtrated dye was determined. The effect of contact time on removal of violet B by AS, WS, PS, TW and $\mathrm{OP}$ as a function of time is shown in Fig. 4.The adsorption increases with increasing of contact time. Obviously, the adsorption equilibrium was attained after stirring for $90 \mathrm{~min}$. It was found that more than $80 \%$ removal of violet B was occurred in the first 90 min of contact time, and thereafter the rate of adsorption was found to be slow. The efficiency of activity of sorbents were as follow: Almond shell > Orange peel $>$ Pistachio shell $>$ Tea waste $>$ Walnut shell. The high activity of almond shell for violet $B$ removal is due to higher its surface area.

\section{Effect of $\mathrm{pH}$}

The $\mathrm{pH}$ of aqueous solution is an important controlling parameter in theadsorption process. To determine the optimum $\mathrm{pH}$, the $\mathrm{pH}$ value was changed from 2 to 11 with fixed initial concentration of $30 \mathrm{mg} \mathrm{L}^{-1}$ of violet $\mathrm{B}$ and contact time $90 \mathrm{~min}$. Fig. 5shows the effect of $\mathrm{pH}$ on the removal of violet $\mathrm{B}$ from aqueous solution by cellulose agricultural wastes (AS, WS, PS, TW and OP).

Results show that the maximum removal of violet $\mathrm{B}$ is observed at $\mathrm{pH} 11$.It seems, the mechanisms of adsorption was done by electrostatic interaction between sorbents and dye. Low $\mathrm{pH}$ value (2.0-6.0) leads to an increase in $\mathrm{H}^{+}$ion concentration in the system and the surface of the sorbents acquires positive charge by absorbing $\mathrm{H}^{+}$

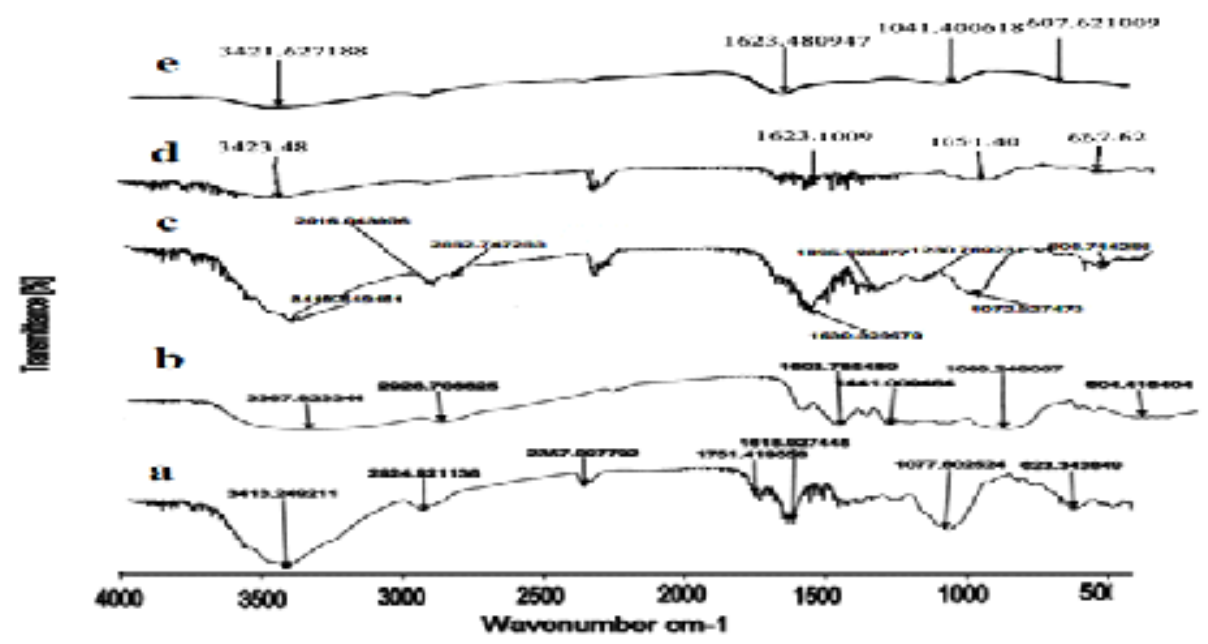

Fig. 2: FTIR of cellulose agricultural wastes ( a-Orange peel, b-Almond shell, c- Pstahio shell, d- walnut shell and e- Teawaste) 
ions. As the shells surface is positively charged at low $\mathrm{pH}$ value, a significantly strong electrostatic repulsion appearbetween the sorbent surface and dye molecules leading to minimum adsorption of dyes.On the other hand, increaseof the $\mathrm{pH}$ value (basic condition) led to increase of the numberof negatively charged sites and the number of positively chargedsites decreases. A negatively charged surface site on the sorbentsis favor for adsorption of violet Bas a cation dye due to theelectrostatic attraction. The lowest adsorption occurred at $\mathrm{pH} 2.0$ and the greatest adsorption
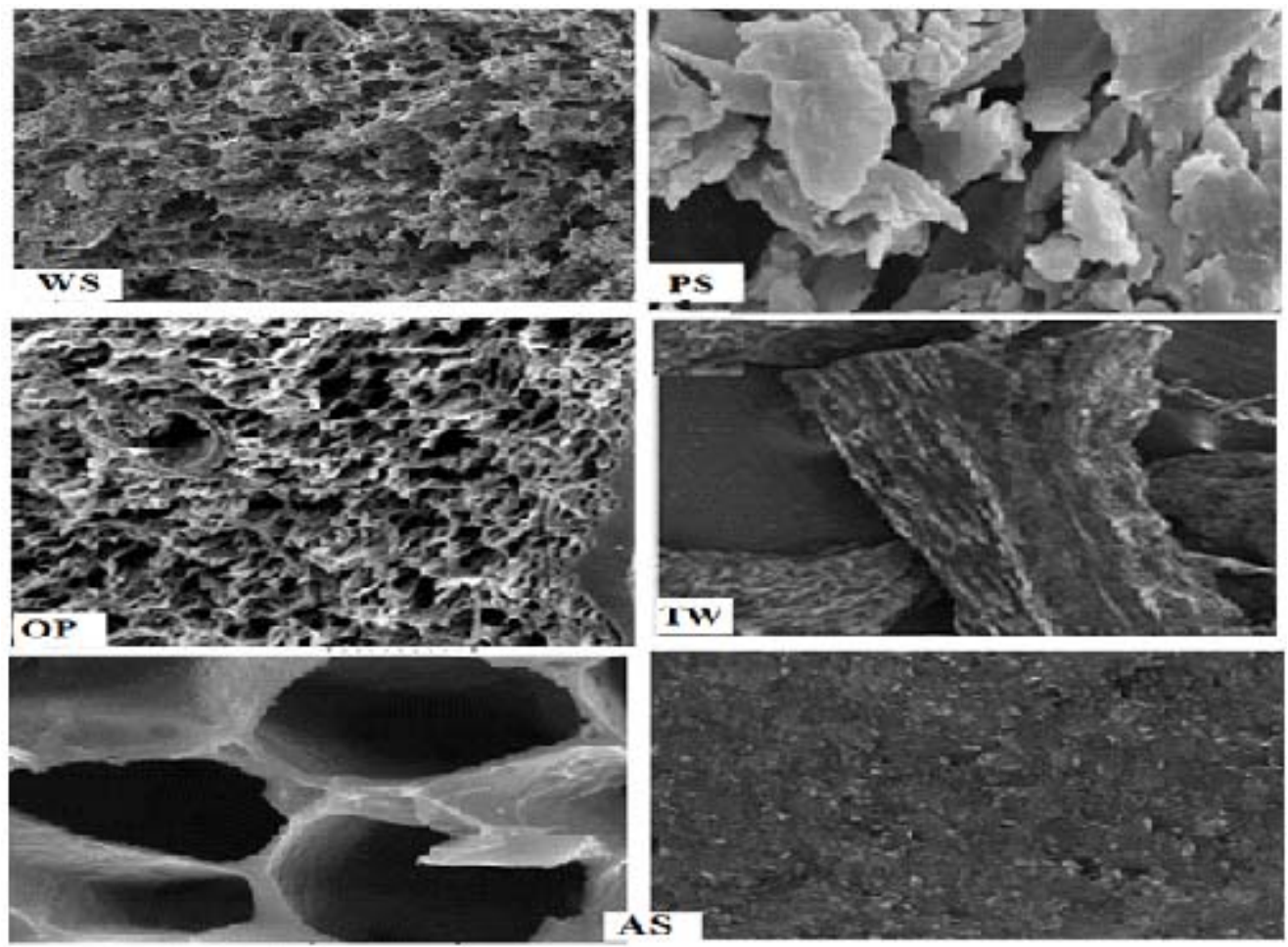

Fig. 3: SEM image of cellulose agricultural wastes (walnutshell (WS), Pstahio shell (PS), Orange peel(OP), Tea waste(TW) and Almond shell (AS))

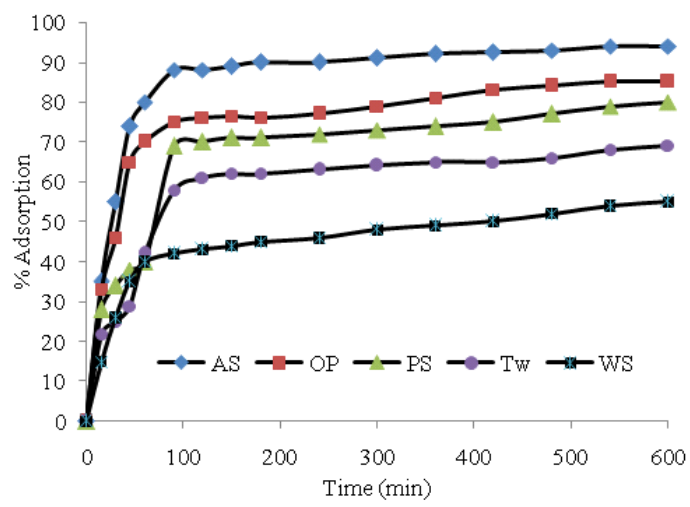

Fig. 4: Effect of contact time for adsorption of violet $B$ by cellulose agricultural wastes (walnut shell (WS), Pstahio shell (PS), Orange peel (OP), Tea waste(TW) and Almond shell (AS))

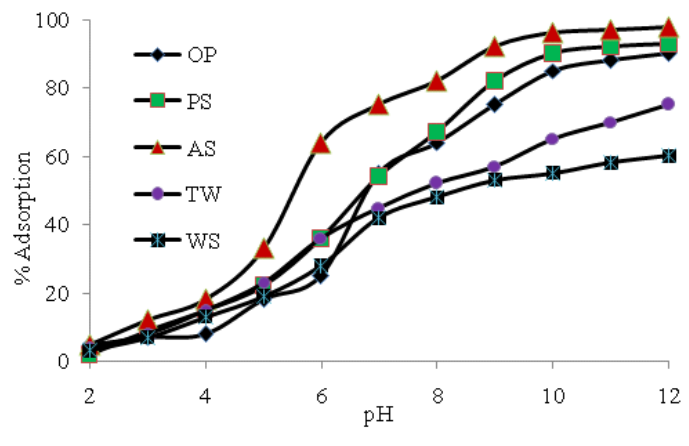

Fig. 5: Effect of $\mathrm{pH}$ of solutions on the adsorption of violet $B$ bycellulose agricultural wastes (walnut shell (WS), Pstahio shell (PS), Orange peel(OP), Tea waste(TW) and Almond shell (AS)) 
occurred at $\mathrm{pH} 11$. Therefore, optimum $\mathrm{pH}$ value 11 for dye adsorption was determined ${ }^{31-33}$.

\section{Effect of adsorbent mass}

The adsorption of violet $B$ onto cellulose agricultural wastes wasstudied by varying of adsorbent quantity $(0.1-3 g)$ in the test solution while keeping the initial dye concentration $\left(30 \mathrm{mg} \mathrm{L}^{-1}\right)$, temperature $\left(25 \pm 1^{\circ} \mathrm{C}\right)$ andcontact time $90 \mathrm{~min}$. The effect of different adsorbent dosages within the range $0.1-3 \mathrm{~g}$ on the removal of violet $B$ by cellulose agricultural wastes (walnut shell (WS), Pstahio shell (PS), Orange peel (OP), Tea waste(TW) and Almond shell (AS)) is shown in Figure 6.

The percentadsorption was increased with adsorbent dosage from $0.1-1.0 \mathrm{~g}$ under the optimized conditions.Increase in adsorption with adsorbent dose can beattributed to increased adsorbent surface area andavailability of more adsorption sites. The removal more than $1.0 \mathrm{~g}$ of adsorbent dosage is only marginal. However, after the attainment of a critical dosage $(1.0 \mathrm{~g})$, the percentage removal slowly increased. This may be attributed to overlapping or aggregation ofadsorbent surface area available to dye and an increase indiffusion path length.

\section{Effect of initial concentration of violet B}

The effect of initial violet $B$ concentration on the adsorption process was investigated at constant concentration of cellulose agricultural waste sorbents $(1.0 \mathrm{~g})$ and different initial violet $B$ concentrations (5-50 $\left.\mathrm{mg} \mathrm{L}^{-1}\right)$. High percentage removal of violet $B$ dye was observed for lower concentration of dye for all adsorbents. The decrease in adsorption, with increasing of concentration of dye is attributed to the increase in the mass transfer driving force.

\section{Adsorption kinetic study}

Adsorption kinetic is important from the point of view tocontrol the process efficiency. The adsorption of a solute by a solid in aqueous solution is a phenomenon with often complex kinetics. The adsorption rate is strongly influenced by several parameters related to the state of the solid, generally having very heterogeneous reactive surface, and to the physicochemical conditions under which adsorption is carried out. Various kinetic models

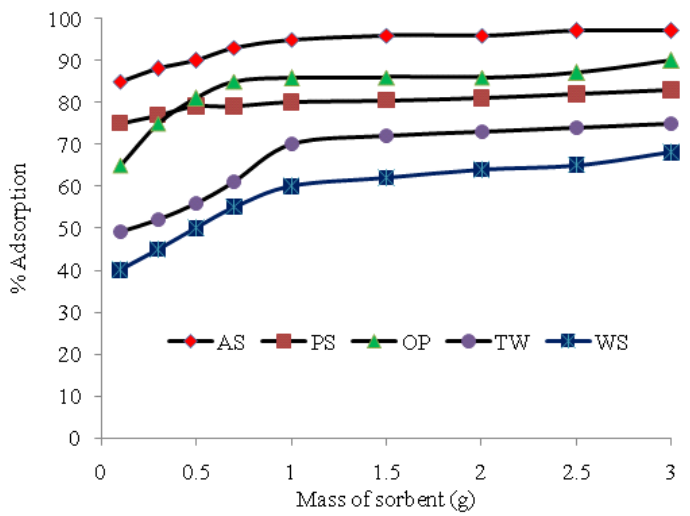

Fig. 6: Effect ofsorbent dosageon the adsorption of violet $B$ bycellulose agricultural wastes (walnut shell (WS), Pstahio shell (PS), Orange peel(OP), Tea waste(TW) and Almond shell (AS))

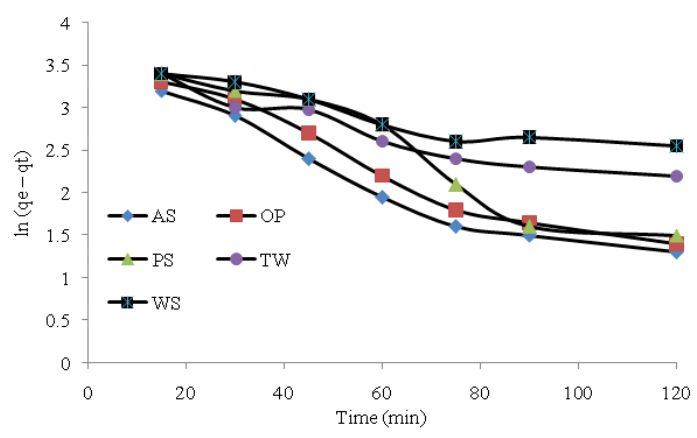

Fig. 7: Pseudo-first-order kinetic model of adsorption of violet $B$ bycellulose agricultural wastes(walnut shell (WS), Pstahio shell (PS), Orange peel(OP), Tea waste(TW) and Almond shell (AS))at $25^{\circ} \mathrm{C}$

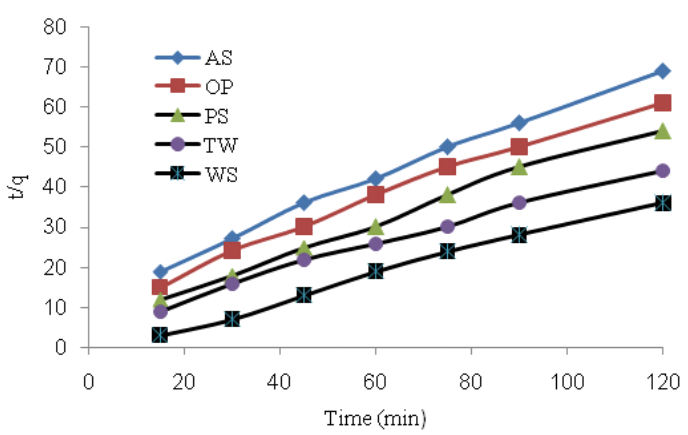

Fig. 8: Pseudo-second-order kinetic model for adsorption of $f$ violet $B$ bycellulose agricultural wastes (walnut shell (WS), Pstahio shell (PS), Orange peel (OP), Tea waste(TW) and Almond shell (AS))at $25^{\circ} \mathrm{C}$ 
have been used by various researchers, where the pseudo-first-order ${ }^{34}$ and pseudo-second-order models were studied ${ }^{35,36}$. The pseudo-first order model assumes that the rate of change of solute uptake with time is directly proportional to difference in saturation concentration and amount of solid uptake with time $^{34}$.

$$
\ln \left(q_{e}-q_{t}\right)=\ln q_{e}-k_{1} t
$$

Where $q_{e}$ and $q_{t}$ are the amounts of dye adsorbed per unite mass of the adsorbent $\left(\mathrm{mg} \mathrm{g}^{-1}\right)$ at equilibrium and time $t$, respectively and $k_{1}$ is the rate constant of adsorption $\left(\min ^{-1}\right)$. When $\ln \left(q_{e}-q_{t}\right)$ was plotted against time, a straight line should be obtained with a slope of $k_{1}$, if the first order kinetics is valid.

The pseudo-second order model as developed by Ho and McKay ${ }^{35,36}$ has the following form:

$t / q_{t}=t / q_{e}+1 /\left(k_{2} q_{e}^{2}\right)$

Where $q_{e}$ and $q_{t}$ represent the amount of dye adsorbed $\left(\mathrm{mg} \mathrm{g}^{-1}\right)$ at equilibrium and at any time. $\mathrm{k}_{2}$ in the rate constant of the pseudo-second order equation $\left(\mathrm{g} \mathrm{mg}^{-1} \mathrm{~min}^{-1}\right)$. A plot of $\mathrm{t} / \mathrm{q}$ versus time $(t)$ would yield a line with a slope of $1 / q_{e}$ and an intercept of $1 /\left(\mathrm{k}_{2} \mathrm{q}_{\mathrm{e}}{ }^{2}\right)$, if the second order model is a suitable expression.

The plot between $\ln \left(q_{e}-q_{t}\right)$ versus time $t$ shows the pseudo first order model and the plot of $t /$ $q$ versus time $t$ shows the pseudo second order model (Figs 7 and 8), respectively. The kinetic model with a higher correlation coefficient $R^{2}$ was selected as the most suitable one (Table 2). The results show that adsorption kinetics of violet Bfitted well by pseudo-second-order kinetic model ${ }^{29}$.

Kinetic parameters for adsorption of violet $B$ bycellulose agricultural wastes

\section{Adsorption isotherm}

Adsorption capacity and adsorption behavior of violet $B$ bycellulose agricultural wastes can be illustrated by adsorption isotherm. The most widely accepted surface adsorption models for single-solute systems are the Langmuir and
Freundlich models. The Langmuir isotherm assumes a surface with homogeneous binding sites, equivalent sorption energies, and no interaction between adsorbed species. Its mathematical form is written as:

$$
\mathrm{C}_{\mathrm{e}} / \mathrm{q}_{\mathrm{e}}=\left(1 / \mathrm{q}_{\max } \mathrm{k}_{\mathrm{L}}\right)+\mathrm{C}_{\mathrm{e}} / \mathrm{q}_{\max }
$$

Where, $\mathrm{q}_{\max }$ and $\mathrm{k}_{\mathrm{L}}$ represent the maximum adsorption capacity for the solid phase loading and the energy constant related to the heat of adsorption respectively. A plot of $C_{e} / q_{e}$ versus $C_{e}$ gives $K_{L}$ and $\mathrm{q}_{\max }$ if the isotherm follows the Langmuir equation. The Freundlich isotherm is an empirical equation based on:

$$
q e=K_{F} C_{e}^{1 / n}
$$

$$
\log q e=\log K_{F}+1 / n \log C e
$$

Where, $\mathrm{k}_{\mathrm{F}}\left(\mathrm{L} \mathrm{g} \mathrm{g}^{-1}\right)$ and $\mathrm{n}$ are Freundlich constants related to adsorption capacity and adsorption intensity, respectively. The intercept $\mathrm{K}_{\mathrm{F}}$ obtained from the plot of $\log q_{e}$ versus $\ln C_{e}$ is roughly a measure of the sorption capacity and the slope $(1 / n)$ of the sorption intensity. Results from the Langmuir and Freundlich analysis of the adsorption of violet $\mathrm{B}$ bycellulose agricultural wastes are also reported in Table 3. The correlation coefficient values indicate that the Langmuir model describes better the adsorption of violet $B$ bycellulose agricultural wastes.

Langmuir and Freundlich isotherm constants for adsorption of violet B bycellulose agriculturalwastes (walnut shell (WS), Pstahio shell (PS), Orange peel (OP), Tea waste (TW) and Almond shell (AS))

\section{CONCLUSION}

Low-cost agricultural waste material was used as adsorbent for adsorption of violet B from aqueous solutions. The adsorption process was attained equilibrium within $90 \mathrm{~min}$ of contact time and $\mathrm{pH}$ 11. Kinetic studies were made for the adsorption of violet $\mathrm{B}$ from aqueous solutions ontoagricultural waste. The kinetic was found to be best-fit pseudo-second- order equation. The Langmuir and Freundlich adsorption models were 
used to express the sorption phenomenon of violet dye. The data obtained were in good agreement with the Langmuir isotherm model.

\section{ACKNOWLEDGEMENTS}

The authors wish to thank Islamic Azad University of Yazd (IAUY) for the ûnancial support of this work. This thank co-workers and technical staff in the chemistry department help during various stages of this work.

\section{REFERENCES}

1. Saha, C.;Text Dyer Printer XXIX ,1996, 21, 13-26.

2. Phillips, D. A. S. ;J. Soc. Dyers Color. 1996, 112, 183-186.

3. Ramakrishna, K.R.; Viraraghavan, T.;Water Sci. Technol. 1997, 36,189-196.

4. Bozdogan, A.; Goknil, H.; MU Fen. Billimeri. Dergisi.Sayi. 1987, 4, 83-90.

5. Majewska-Nowak, K.; Desalination, 1989, 71, 127-135.

6. Shendrik, O.R.; Kimiyi. Technol. Vody.1989, 11, 467-471.

7. Ding, Z.; Min, C.W. ;Hui, W.Q. ;Water Sci. Technol. 1987, 19(3/4), 39-44.

8. Abdelwahab, O.; El Nemr, A.; El-Sikaily, A.;Khaled, A.;UlvaLactuca, Chem. Ecol. 2009, 22, 253-266.

9. El-Sikaily, A.;Khaled, A.; El Nemr, A.; Abdelwahab, O.;Ulvalactuca, Chem. Ecol. 2009, 22, 149-157.

10. Ho, Y.S.; Chiang, T.H.;Hsueh, Y.M.; Process Biochem. 2005, 40, 119-124.

11. Ozacar, M.;Engil, IÙ.A. S.;Process Biochem. 2005, 40, 565-572.

12. Akkaya, G. ;Uzun, IÙ.; Guzel, F.; Dyes Pigments, 2007, 73, 168-177.

13. Cooper, P.;Soc Dyers and Colorists, Alden Press,Oxford, 1995.

14. Elnemr, A., Abdelwahab, O. ; El-sikaily, A.; khaled, A.; J. Hazard. Mater. 2009, 161, 102110.

15. Hashemian,S.; Salimi,M.; Chem. Eng. J. 2012, 188, 57-63.

16. Hashemian, S.; Mirshamsi, M.;J. Indust. Eng. Chem. 2012, 18, 2010- 2015.

17. Robinson, T.; Chandran,B.; Nigam, P.; Environ. Int. 2002, 28, 29-33.

18. Kazemipour,M.; Ansari, M.; Tajrobehkar, S.; Majdzadeh,M.;Kermani,H. R.;J. Hazard. Mater. 2008, 150(2), 322-327.

19. Attia,A. A.; Girgis, B. S.;Khedr,S. A.;J. Chem.
Technol. Biotechnol. 2003, 78(6), 611-619.

20. Annadurai, G.; Juang,R. S.; Lee,D. J.;J. Hazard.Mater. B. 2002, 92, 263-274.

21. Mohan,D.; Singh,K. P.;Sinha,S.; Gosh, D.; Carbon, 2005, 43, 1680-1693.

22. Sundaram,M. M.;Sivakumar, S.; J. Chem. Res. 2012, 4(4), 2047-2054.

23. Wang, X. S.; Zhou,Y.; Jiang,Y.; Sun,C.;J. Hazard. Mater.2008, 157 (2-3), 374-385.

24. Chen,S. H.;Zhang,J.; Zhang, C. L.; Yue,Q. Y.; Li,Y.; Li,C.;Desalination, 2010, 252,149-156.

25. Mehrasbi, M. R.;Farahmandkia,Z.; Taghibeigloo, B.; Taromi,A.; Water Air Soil Pollut, 2009, 199, 343-351.

26. Ozdes,D.;Gundogdu,A.; Duran,C.;Senturk, H. B.; Separ. Sci. Technol. 2010, 45, 2076-2085.

27. Sahranavard,M.;Ahmadpour,A.;Doosti, M. R.; Eur. J. Sci. Res. 2011, 58 (3), 392-400.

28. Khaled, A.; Elnemr, A.; El-sikaily, A. Abdelwahab, O.; J. Hazard. Mater.2009, 165, 100-110.

29. Hashemian, S.; Salari, K.; Atashi, Z.; J. Indus. Eng. Chem. 2014, 20, 1892-1900.

30. Mehrasbi, M. R.; Farahmandkia, Z. ; Taghibeigloo,B.I; Taromi, A.; Water Air Soil Pollut, 2009, 199, 343-351.

31. Hashemian, S.; Salari, K.; Salehifar, H.; Atashi, Z.;J. Chem. Volume 2013, Article ID 283274, 10 pages, http://dx.doi.org/10.1155/2013/ 283274

32. Hashemian, S; Inter. J. Phys. Sci. 2011, 6(27): 6257-6267.

33. Annadurai, G.; Juang, R. S.; Lee, D. J.; J.Hazard.Mater. B, 2002,92,263-274.

34. Lagergren, S.; Handlingar, 1898, 24, 1-39.

35. Ho, Y. S.; McKay, G.; Wase, D. A. J.; Foster, C. F.;Ads. Sci. Technol. 2000, 18, 639-650.

36. Ho, Y.S., McKay, G., Canadian J. Chem. Eng. 1998, 76, 822-827.

37. Hashemian, S.; Salari, K.; Atashi, Z.; J. Indus. Eng. Chem. 2014, 20, 1892-1900. 